\title{
Efeito do armazenamento sobre \\ a cor de filmes de quitosana
}

\section{Effect of the storage on the color of chitosan films}

\author{
Nathalia Valderrama Bohórquez ${ }^{*}$, Néstor Ariel Algecira Enciso² e William Albaracín Hernández ${ }^{3}$ \\ 'Instituto de Ciencia y Tecnología de Alimentos, Facultad de Ciencias Agrarias, \\ Universidad Nacional de Colombia, Bogotá D.C., Colombia \\ ${ }^{2}$ Laboratorio de Polímeros, Facultad de Ingeniería, Universidad Nacional de Colombia, \\ Bogotá D.C., Colombia \\ ${ }^{3}$ Facultad de Ingeniería Agroindustrial, Universidad de Nariño, Pasto, Nariño, Colombia \\ *nvalderramab@unal.edu.co
}

\begin{abstract}
Resumo
Este trabalho teve como objetivo determinar o efeito da inclusão de óleos essenciais (EOs) e do armazenamento na cor dos filmes de quitosana $(\mathrm{CH})$ para os parâmetros de $\mathrm{L}^{*}, \mathrm{a}^{*}, \mathrm{~b}^{*}$ e $\Delta \mathrm{E}$. Os óleos essenciais de tomilho (TEO) e alecrim (REO) foram incluídos em concentrações de 0,5:1 e 1:1 p/p (EOs:CH), assim como suas combinações 50/50 (TEO:REO). Os filmes foram armazenados a temperaturas de $5{ }^{\circ} \mathrm{C}, 20{ }^{\circ} \mathrm{C}$ e, $33{ }^{\circ} \mathrm{C}$ e umidade relativa do ar de $60 \%, 75 \%$ e, $93 \%$ durante quatro semanas. Os parâmetros da cor foram determinados por refletância com componente especular incluído (RSIN) e por refletância com componente especular excluído (RSEX), usando seis padrões de fundos diferentes. A inclusão e o aumento da concentração de óleos essenciais, assim como o aumento do tempo, da temperatura e da umidade e o padrão de fundo alteraram os valores das variáveis resposta.
\end{abstract}

Palavras-chave: aditivos alimentares, polímeros modificados, quitosana.

\begin{abstract}
The aim of this study was to determine the effect of the thyme and rosemary essential oils (EOs) inclusion and the storage on the chitosan $(\mathrm{CH})$ films color for the parameters $\mathrm{L}^{*}, \mathrm{a}^{*}, \mathrm{~b}^{*}$ and $\triangle \mathrm{E}$. The thyme (TEO) and rosemary (REO) essential oils were included in 0,5:1 and 1:1 p/p (EOs:CH), as well as their combination 50/50 (TEO:REO). The films were stored at temperatures of $5{ }^{\circ} \mathrm{C}, 20^{\circ} \mathrm{C}$ and $33{ }^{\circ} \mathrm{C}$ and relative humidity of $60 \%, 75 \%$ and $93 \%$ during four weeks. The colour parameters were determined by reflectance with included specular component (RSIN) and reflectance with excluded specular component (RSEX) using six different standard backdrops. Most of the results provides that the standard backdrops, the inclusion and the increasing concentration of the essential oils, as well as the time, temperature and humidity influenced the response of the variables.
\end{abstract}

Keywords: food additives, modified polymers, chitosan.

\section{Introdução}

A quitosana $(\mathrm{CH})$ (poli-(1,4)-2-amino-2-desoxi-Dglicose) é obtida a partir de um processo de desacetilação da quitina (poli-(1,4)-2-acetamida-2-PD-desoxi-glicose) por métodos enzimáticos ou químicos. Os avanços recentes têm-se centrado na inclusão de compostos químicos nas embalagens que melhoram as propriedades dos filmes de $\mathrm{CH}^{[1-5]}$. Os óleos essenciais são incluídos nas matrizes poliméricas de $\mathrm{CH}$ para melhorar as suas propriedades antimicrobianas e antioxidantes ${ }^{[6,7]}$. A natureza não polar do óleo essencial e as interações entre os componentes do óleo e da matriz polimérica podem gerar uma diminuição do brilho e da transparência das películas, devido à rugosidade da superfície apresentada pelo fenômeno de floculação das gotas de óleo durante a secagem ${ }^{[6,8,9]}$.
As condições de armazenamento como a umidade, a temperatura e o tempo, modificam as propriedades físicas dos filmes ${ }^{[10,11]}$. Isto pode ser devido à recristalização das moléculas de $\mathrm{CH}$, à perda de umidade e de plastificante na matriz polimérica, à lenta reacetilação dos grupos amino e as variações do volume livre ${ }^{[12-14]}$. Além disso, as propriedades como luminosidade diminui e o valor de b* aumenta, devido as reações de obscurecimento não enzimático ${ }^{[15]}$.

A aplicação dos óleos essenciais e dos recobrimentos da quitosana nos alimentos prolonga a sua vida útil em até onze dias nas amostras de peito do peru embalado ao vácuo e em até dois dias nas amostras em frango cozido embalado ao vácuo. Esses compostos demonstraram efeitos antimicrobianos e antioxidantes sem afetar negativamente as propriedades sensoriais ${ }^{[16,17]}$. Além disso, a aplicação de 
recobrimentos em alimentos previne a descoloração durante o armazenamento ${ }^{[18-24]}$, porém a maioria dos estudos não reportam mudanças na cor ${ }^{[20-24]}$. Só alguns estudos referem que a luminosidade muda, por exemplo, quando são aplicados sobre a casca de ovo e à superfície de filé de salmão ${ }^{[18,19]}$. No entanto, outros estudos determinam que a aplicação de quitosana favorece os atributos sensoriais de qualidade de morangos recobertos, tais como a aparência externa, a aceitabilidade visual e a redução do obscurecimento das amostras, além de diminuir as mudanças da cor na pele de mamão e aumentar a luminosidade da casca de ovos durante 5 semanas de armazenamento ${ }^{[25-27]}$.

Alguns autores tem identificado que os filmes de quitosana são altamente translúcidos, porém alguns deles apresentam uma aparência ligeiramente amarelada ${ }^{[28,29]}$. Quando os recobrimentos comestíveis são aplicados sobre a superfície dos alimentos, a cor destes é medida usando mecanismos de refletância ${ }^{[30-32]}$. Segundo Lee \& Powers ${ }^{[33]}$, as mudanças de cor de resinas no modo de transmitância pode ser grosseiramente estimadas pelo modo de refletância ${ }^{[33]}$.

Quando a cor de materiais translúcidos é medida por reflexão, o fundo sobre o qual são aplicados e a sua espessura podem influenciar consideravelmente a cor que é observada ${ }^{[34-36]}$. Segundo Sánchez-Zapata et al. ${ }^{[35]}$, a cor do patê de atum somente muda quando as amostras de menores espessuras são medidas sobre superfícies de cerâmica e de plástico brancos.

A cor é importante porque afeta diretamente a aceitabilidade dos consumidores ${ }^{[37]}$. No caso de filmes comestíveis, é necessário realizar a caracterização colorimétrica, porque se determinam os efeitos da aplicação de filmes comestíveis na cor dos alimentos revestidos.

O objetivo deste artigo foi determinar o efeito da inclusão de óleos essenciais de tomilho e alecrim e das condições de armazenamento em temperaturas de $5{ }^{\circ} \mathrm{C}, 20{ }^{\circ} \mathrm{C}$ e $33{ }^{\circ} \mathrm{C}$ e umidades relativa do ar de $60 \%, 75 \%$ e, $93 \%$ durante quatro semanas na cor dos filmes de $\mathrm{CH}$ comparando seis padrões de cores diferentes de fundo.

\section{Experimental}

\subsection{Preparação dos filmes}

A solução foi preparada em meio aquoso de ácido lático $\left(1,0 \%\right.$ v/v). Quitosana, marca Kitoflokk ${ }^{\mathrm{TM}}$, grau de acetilação médio (80\%) e baixo peso molecular e viscosidade baixa $(13 \mathrm{cP})$, foi adquirida de NorwegianChitosan, Aspertunet, Norway e adicionada numa concentração $2 \%, \mathrm{p} / \mathrm{v}^{[38]}$ usando um equipamento Ultra-Turrax ${ }^{\circledR}$. Essa disolução foi seguidamente filtrada na temperatura ambiente para remover as impurezas, usando um filtro qualitativo Boeco ${ }^{\circledR}$ (BoeckelCo., Hamburg, Germany) e esterilizada a uma temperatura de $121^{\circ} \mathrm{C}$ durante 15 minutos.

A dissolução foi misturada com $4 \%$ de polissorbato 80 e $16 \%$ de glicerol, quantidades baseadas no peso do polímero em solução. Os óleos essenciais de tomilho (TEO) e alecrim (REO) foram incluídos em proporções de 0,5:1 ou 1:1, baseadas no peso do polímero em solução (EOs:CH). Os tratamentos com a mistura de óleos essenciais foram incluídos na proporção 50/50 (TEO:REO). Cada dissolução foi homogeneizada a 30,000 rpm durante 5 minutos usando um equipamento Ultra-Turrax ${ }^{\circledR}$ e desgaseificada numa câmara de vácuo em temperatura ambiente. Os filmes foram preparados com uma solução de 10 gramas por cada placa de petri de $10 \mathrm{~cm}$ de diámetro (aproximadamente 1,27 mg CH/cm2). Os filmes controle foram preparados seguindo o mesmo protocolo, mas sem a adição dos EOs. Após, as dissoluções foram secadas a $30{ }^{\circ} \mathrm{C}$ durante 65 horas.

\subsection{Propriedades físicas}

pH. O pH das soluções foi determinado usando um medidor padrão de $\mathrm{pH}$ (Orion 920A, Sigma-Aldrich, CA, EUA).

Espessura. A espessura foi determinada usando um micrômetro digital com uma precisão de 0,001 milímetros (Coolant Proof Micrometer 293, Mitutoyo Measuring Instruments, Kanagawa, Japan). Os valores foram calculados como a média de 10 medições em cada filme.

Determinação da cor dos filmes de quitosana. Os parâmetros de cor foram determinados por reflexão com um colorímetro COLORQUEST XE (Hunterlab, Reston, VI, USA) com iluminante D65 e observador a $10^{\circ}$. As medições foram feitas por refletância com componente especular incluído (RSIN) e por refletância com componente especular excluído (RSEX). Os valores $L^{*}$ (luminosidade), a* (intensidade de vermelho e verde) $\mathrm{e} \mathrm{b}^{*}$ (intensidade de amarelo e azul), $\Delta \mathrm{E}$ (diferença e cor) foram obtidos como a média de dez medições em cada filme. Para a determinação dos parâmetros, os filmes foram sobrepostos em seis padrões de cores diferentes: amarelo $\left(L^{*}=93,2 ; a^{*}=-8,28\right.$ e b* $\left.=33,23\right)$, branco $\left(L^{*}=91,99\right.$; $\left.\mathrm{a}^{*}=-0,75 \mathrm{e} \mathrm{b}^{*}=1,8\right)$, vermelho $\left(\mathrm{L}^{*}=40,35 ; \mathrm{a}^{*}=39,66\right.$ e $\left.b^{*}=10,99\right)$, rosa $\left(L^{*}=83,15 ; a^{*}=17,39\right.$ e b* $\left.=3,23\right)$, verde $\left(L^{*}=56,84 ; a^{*}=-21,82\right.$ e $\left.b^{*}=9,31\right)$ e verde maçã $\left(\mathrm{L}^{*}=89,44 ; \mathrm{a}^{*}=-10,55 \mathrm{e} \mathrm{b}=13,01\right)$.

\subsection{Armazenamento}

Os filmes obtidos da mistura dos óleos essenciais (TR1) de tomilho e alecrim (combinações 50/50) foram armazenados à temperatura $(\mathrm{T})$ de $5{ }^{\circ} \mathrm{C}, 20^{\circ} \mathrm{C}$ e $33^{\circ} \mathrm{C}$ e umidade relativa (H) de $60 \%, 75 \%$ e, $93 \%$ durante quatro semanas (S). Os filmes controle foram preparados identicamente, mas sem a adição dos óleos essenciais (C).

\subsection{Análise estatística}

Análise Estatística. Análise multivariada $(p<0,05)$ usando o pacote estatístico Statgraphics ${ }^{\circledR}$ Centurion XV (StatPoint Technologies Inc, Warrenton, Virginia, USA). Reportaram-se as diferenças significativas pelo método de mínima diferença significativa (DMS) de Fisher com dez repetições.

\section{Resultados e Discussões}

\subsection{Efeito da adição dos óleos essenciais nas propriedades físicas dos filmes}

Os pH foram estão entre 4,95-5,36. A adição dos óleos essenciais não modificaram o pH das dissoluções.

As espessuras dos filmes foram registradas entre 0,063-0,104 mm e estão apresentadas na Figura 1. A espessura da película depende da sua composição ${ }^{[39]}$. A inclusão dos 


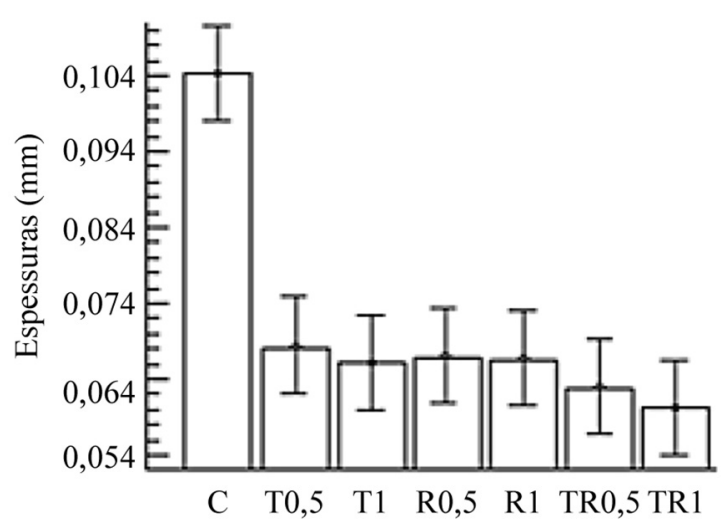

Figura 1. Espessura dos filmes. C: amostra controle, tipo e concentração de óleos essenciais: tomilho $(\mathrm{T})$, alecrim $(\mathrm{R})$, mistura de tomilho e alecrim (TR), 0,5 e 1: proporção dos óleos essenciais em relação a quitosana.

óleos essenciais diminuiu significativamente a espessura dos filmes. Estes resultados concordam com os resultados de Sánchez-González et al. ${ }^{[40]}$, que concluiu que a espessura foi influenciada pela composição da película. No entanto, eles são opostos aos resultados de Hosseini et al. ${ }^{[41]}$ que não reportam diferenças na espessura das películas.

\subsection{Efeito da adição dos óleos essenciais nas propriedades colorimétricas dos filmes}

$\mathrm{O}$ efeito da adição de óleos essenciais, do aumento da concentração destes óleos e do padrão de fundo usado no parâmetro $a^{*}$ foram apresentados na Figura $2 \mathrm{a}$ e na Figura 2b. Para os padrões vermelho e rosa, a inclusão dos óleos essenciais e o aumento da concentração diminuem a intensidade do parâmetro $-\mathrm{a}^{*}$. Contudo, para os padrões amarelo, branco, verde e verde maçã o comportamento é oposto. Essa tendência ainda apresenta-se por RSIN e por RSEX.

Analisando-se os resultados dos valores de $b^{*}$ (Figura 3a e Figura 3b), para o padrão amarelo nos filmes de tomilho 1:1 (AE:CH), este valor aumenta. Mas nos filmes de alecrim 0,5:1 (AE:CH) diminui RSIN e por RSEX. Para o padrão verde maçã, nos filmes de alecrim e na mistura de tomilho e alecrim, o valor $b *$ diminui por RSIN, mas por RSEX o valor $b^{*}$ aumenta com a inclusão da mistura de tomilho e alecrim. Para o padrão rosa, o valor $b^{*}$ por RSIN aumenta nos filmes de tomilho 0,5:1 (AE:CH) e na mescla TR1:1 (AE:CH), mas por RSEX se mantém estável. Para os padrões verde e vermelho, o valor b* por RSIN e por RSEX diminui nos filmes com inclusão de alecrim (AE:CH), assim como nos filmes de tomilho 1:1 (AE:CH). Para o padrão branco, o valor $b^{*}$ aumenta com a inclusão dos óleos essenciais.

Estes comportamentos diferentes podem ocorrer devido ao tipo de óleo usado. Du et al. ${ }^{[42]}$ encontraram diferentes efeitos sobre alguns parâmetros de cor quando óleos essenciais de canela e cravo foram incluídos. A inclusão de óleo essencial de tomilho e o aumento de sua concentração incrementam levemente o matiz amarelo dos filmes sem alterar sensorialmente a aparência geral ${ }^{[6]}$.

Além disso, a inclusão de óleos essenciais diminuiu os valores de L*, na maioria dos casos. Somente para

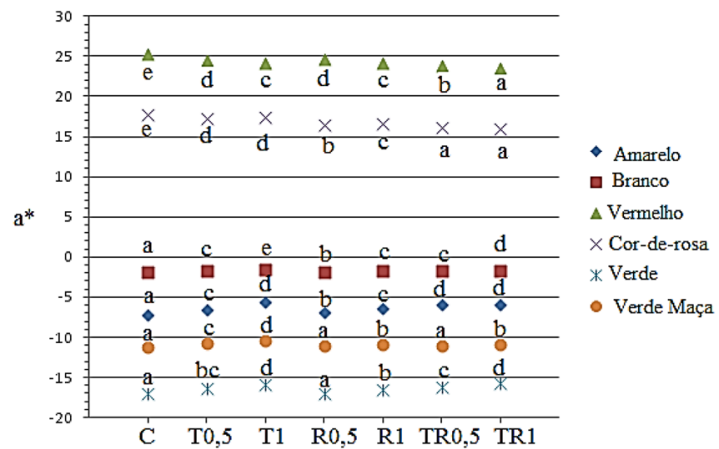

(a)

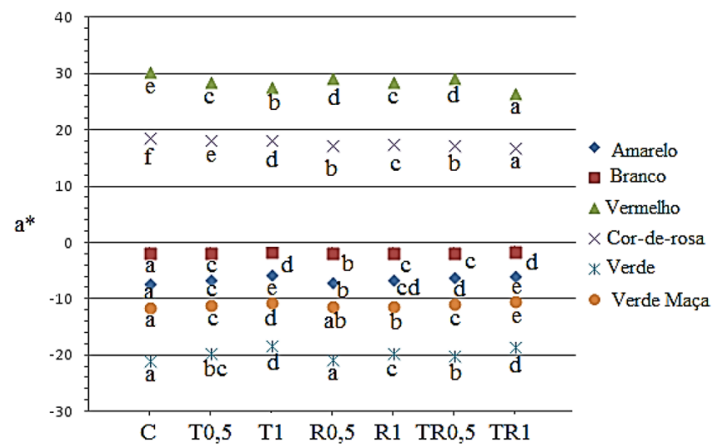

(b)

Figura 2. a*: (a) a* medido por RSIN; (b) a* medido por RSEX. As letras a, b, c, d, e e f e as suas combinações indicam diferenças significativas entre os tratamentos $(p<0,5)$. $a^{*}$ : intensidade de vermelho e verde, $\mathrm{C}$ : amostra controle, tipo e concentração dos óleos essenciais: tomilho $(\mathrm{T})$, alecrim $(\mathrm{R})$, mistura de tomilho e alecrim (TR), 0,5 e 1: proporção dos óleos essenciais em relação a quitosana. por RSIN.

os padrões vermelho (RSIN e RSEX) e verde por RSEX este comportamento foi oposto (Figura 4a e Figura 4b). Resultados similares foram obtidos por Du et al. ${ }^{[42]}$ e por Moradi et al. ${ }^{[43]}$, em que o aumento da concentração de óleos essenciais de canela e extrato de uva diminuiu a luminosidade e a transparência dos filmes. Sanchez-González et al. ${ }^{[44]}$, afirmaram que a inclusão de óleo essencial de tomilho diminuiu o brilho superficial pelo incremento da rugosidade e das irregularidades devido à migração do óleo à superfície.

Igualmente, a inclusão e o aumento da concentração de óleos essenciais aumentam a diferença de cor $(\Delta \mathrm{E})$. Só para o padrão verde este comportamento foi oposto (Figura 5a e Figura 5b). Este fenômeno é atribuído à leve diminuição do parâmetro $L^{*}$ e ao leve incremento do parâmetro $b^{*[45]}$.

\subsection{Efeito do armazenamento nas propriedades físicas dos filmes}

Espessura. A espessura não foi afetada por mudanças na umidade ou temperatura. Durante o período de armazenamento, não foram encontradas diferenças significativas na espessura dos filmes após a segunda semana de armazenamento. No entanto, foram apresentadas diferenças significativas entre as espessuras dos filmes sem armazenamento e dos filmes armazenados (Figura 6). 


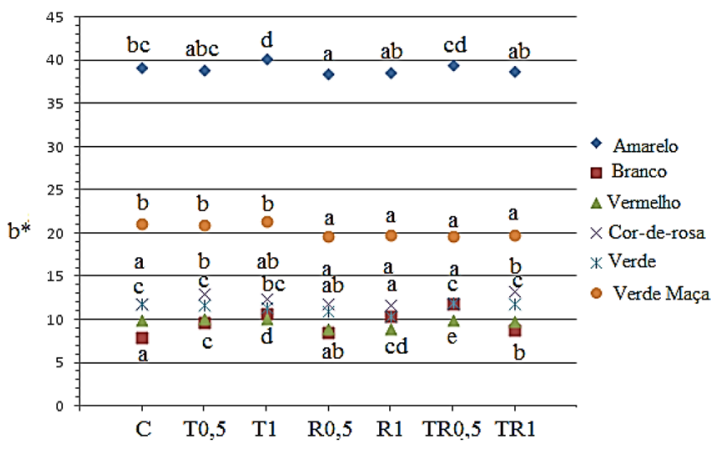

(a)

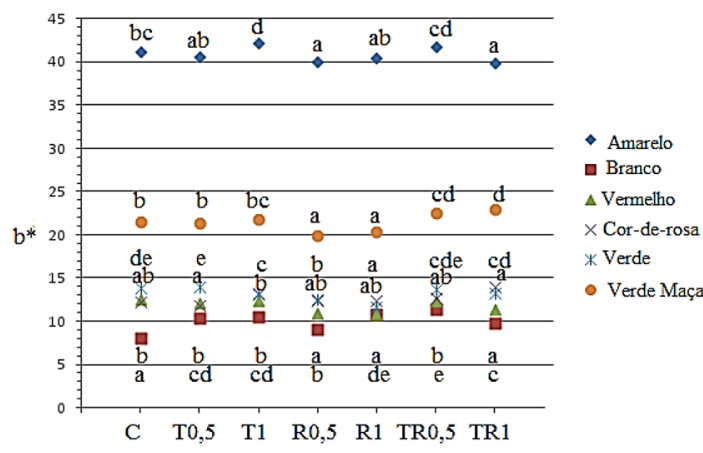

(b)

Figura 3. b*: (a) b* medido por RSIN; (b) b* medido por RSEX. As letras a, b, c, d, e, e as suas combinações indicam diferenças significativas entre os tratamentos $(p<0,5)$. $b^{*}$ : intensidade de amarelo a azul, C: amostra controle, tipo e concentração de óleos essenciais: tomilho (T), alecrim (R), mistura de tomilho e alecrim (TR), 0,5 e 1: proporção dos óleos essenciais em relação a quitosana.

\subsection{Efeito do armazenamento nas propriedades colorimétricas dos filmes}

Observou-se uma diminuição significativa da luminosidade nos filmes com inclusão da mistura dos óleos essenciais para os fundos branco, verde maçã, amarelo, vermelho e rosa e com a exclusão da refletância. Durante o armazenamento, o aumento do tempo e da temperatura de armazenamento, diminuiu a luminosidade com a exceção da luminosidade da Semana 0 (S0) e da Semana 2 (S2) que não foi significativamente diferente (Figura 7).

Além disso, só a humedade relativa de $93 \%$ produziu mudanças significativas em contraste com o fundo amarelo. Porém, nos casos todos foram observadas diferenças significativas entre as amostras armazenadas às umidades relativas de 60\% (H60) e de 75\% (H75) (Figura 8). A diminuição da luminosidade produz filmes mais escuros. O efeito provavelmente é devido às mudanças na estrutura molecular e na composição química da quitosana ${ }^{[38,46]}$. Esses resultados foram similares aos obtidos por Duan et al. ${ }^{[47]}$, que concluíram que um acréscimo do tempo e da temperatura durante o armazenamento tornam as soluções de quitosana mais escuras.

$\mathrm{O}$ aumento do parâmetro a* indica um aumento da intensidade vermelha dos filmes e a diminuição do parâmetro $\mathrm{a}^{*}$ indica um aumento da intensidade verde. Para os padrões

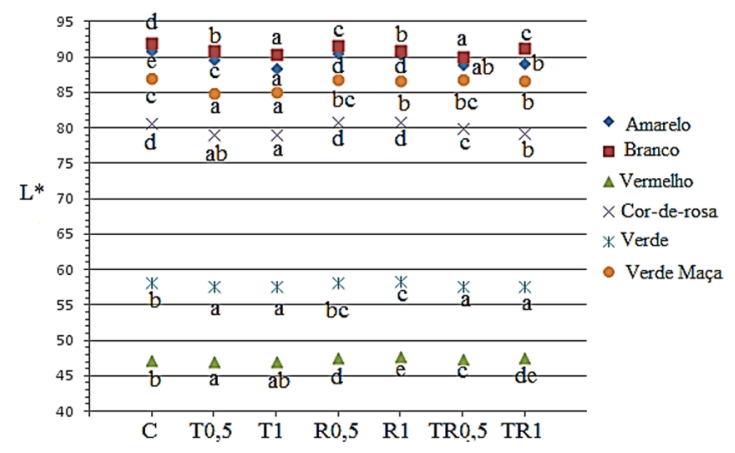

(a)

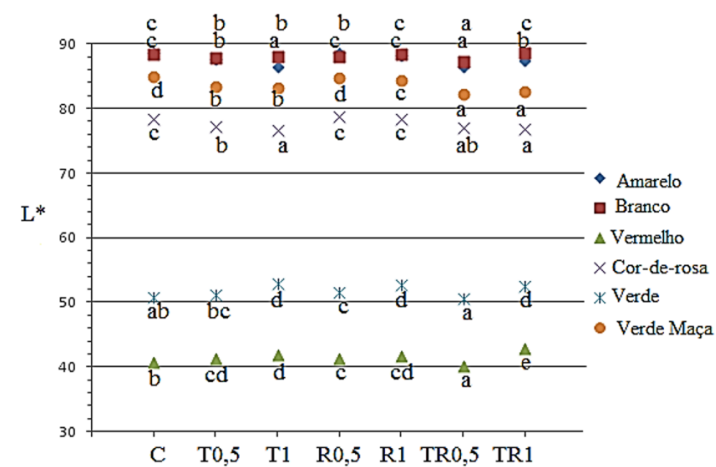

(b)

Figura 4. L*: (a) L* medida por RSIN; (b) L* medida por RSEX. As letras a, b, c, d, e, e as suas combinações indicam diferenças significativas entre os tratamentos $(p<0,5)$. $\mathrm{L}^{*}$ : luminosidade, C: amostra controle, tipo e concentração de óleos essenciais: tomilho(T), alecrim (R), mistura de tomilho e alecrim (TR), 0,5 e 1: proporção dos óleos essenciais em relação à quitosana.

vermelho e rosa, a inclusão dos óleos essenciais diminuiu a intensidade do parâmetro a*. Contudo, para os padrões amarelo, branco, verde e verde maçã o comportamento é oposto (Figura 9). Além disso, a maioria dos filmes reportou um aumento ocasionado pelo aumento do tempo, da temperatura e da umidade durante o armazenamento. Porém, algumas vezes este comportamento foi diferente nos padrões de fundo da cor vermelha e da rosa (Figura 8). No padrão amarelo, o parâmetro a* registrou diferenças significativas entre as umidades de $60 \%, 75 \%$ e $93 \%$, na temperatura de $33{ }^{\circ} \mathrm{C}$, além de registrar diferenças significativas entre as Semanas 0,2 e 4 (S0, S2 e S4, respectivamente), nas temperaturas de armazenamento de $33^{\circ} \mathrm{Ce} 20^{\circ} \mathrm{C}$ para as amostras com a mescla de tomilho e alecreim (TR1) (Figura 10).

Os fatores como a composição do filme, o tempo, a temperatura, a umidade e a refletância afetaram significativamente o parâmetro b* (Figura 11). Segundo Fernandez-Sainz et al. ${ }^{[46]} \mathrm{o}$ aumento do parâmetro $b^{*}$ nos filmes armazenados sugere que os filmes se tornem mais amarelos pelo escurecimento não enzimático. As pesquisas desenvolvidas na área determinaram que a velocidade da reação relaciona-se com a composição do material, à temperatura, ao conteúdo da umidade e ao $\mathrm{pH}$. Cuq et al. ${ }^{[48]}$ concluíram que o efeito do obscurecimento não enzimático foi mais severo depois da primeira semana do armazenamento e até a quinta semana. Além disso, a velocidade do obscurecimento 
foi maior quando a umidade relativa e a temperatura foram mais altas. Contudo, algumas pesquisas não registraram diferenças significativas nas propriedades de cor ainda armazenadas durante 16 semanas $^{[49]}$.

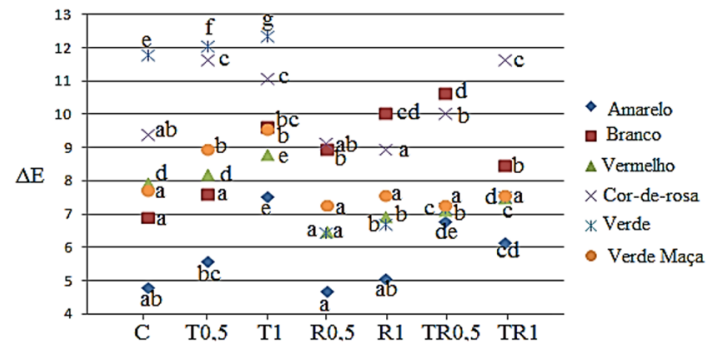

(a)

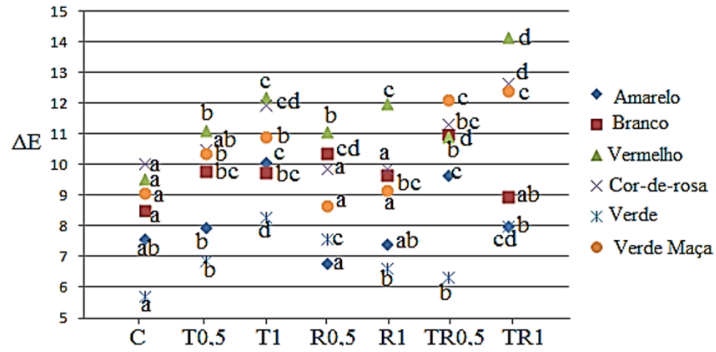

(b)

Figura 5. $\Delta \mathrm{E}$ : (a) $\Delta \mathrm{E}$ medida por RSIN; (b) $\Delta \mathrm{E}$ medida por RSEX As letras a, b, c, d, e, fe g, e as suas combinações indicam diferenças significativas entre os tratamentos $(\mathrm{p}<0,5) . \Delta \mathrm{E}$ : diferença de cor, C: amostra controle, tipo e concentração de óleos essenciais: tomilho(T), alecrim (R), mistura de tomilho e alecrim (TR), 0,5 e 1 : proporção dos óleos essenciais em relação à quitosana.

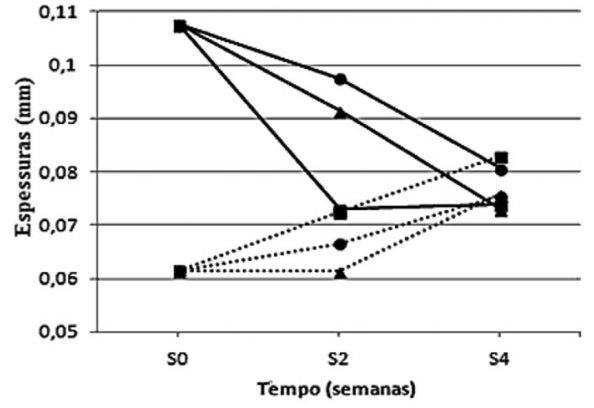

(a)
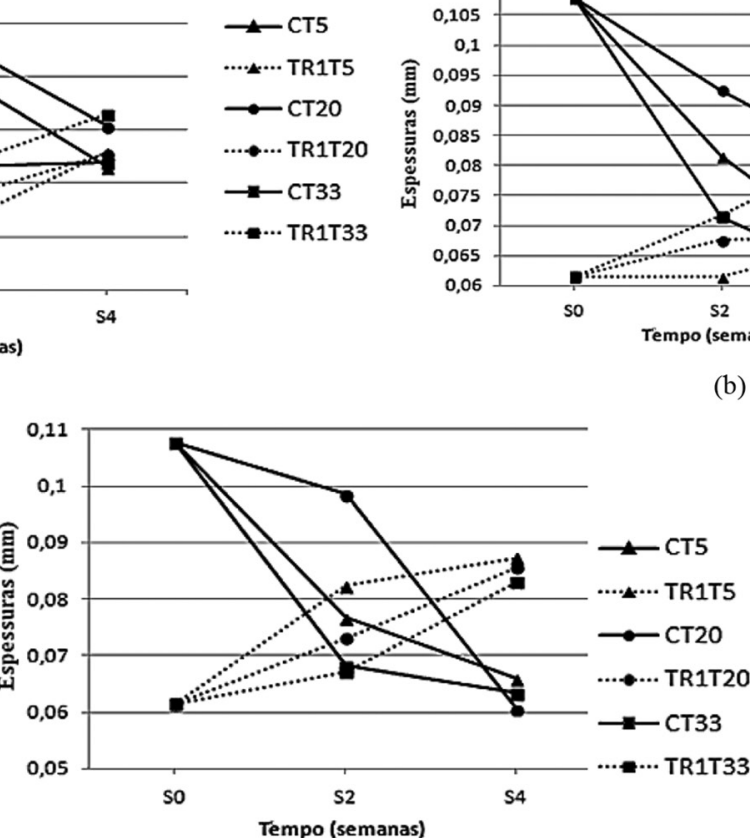

(c)

(b)
Esse estudo revelou que há diferenças significativas no parâmetro $b^{*}$ pela inclusão de óleos essenciais e da exclusão da refletância especular com exceção nas medições sobre o fundo branco. Além disso, o aumento do tempo e a temperatura de armazenamento aumentou o parâmetro b*. O aumento da umidade de armazenamento aumentou os valores do parâmetro b* . No entanto, nos fundos verde, amarelo e vermelho, o efeito da umidade relativa de $75 \%$ (H75) foi significativamente maior que o efeito da umidade relativa de $93 \%$ (H93)

No padrão amarelo, o parâmetro $b$ * registrou diferenças significativas entre a composição dos filmes, as temperaturas $5^{\circ}, 20^{\circ} \mathrm{C}$ e $33{ }^{\circ} \mathrm{C}$, as umidades de $60 \%, 75 \%$ a $93 \%$, nas temperaturas de $20^{\circ} \mathrm{C}$ e $33^{\circ} \mathrm{C}$, além de registrar diferenças significativas entre as amostras da semana 0, 2 e 4 (S0, S2 e S4, respectivamente), sob umidades relativas de armazenamento de $75 \%$ e $93 \%$ (Figura 12 ).

A inclusão de óleos essenciais aumentou significativamente a diferença de cor $(\Delta \mathrm{E})$. No entanto, não registrou diferença sobre o fundo branco (Figura 13). O aumento do tempo de armazenamento aumentou a diferença de cor. Porém, no fundo vermelho as medições de diferença de cor foi significativamente maior na Semana 2 (S2). O aumento da temperatura de armazenamento aumentou a diferença de cor. Porém, no fundo verde maçã a diferença de cor foi significativamente maior nas amostras armazenadas à temperatura de $20^{\circ} \mathrm{C}(\mathrm{T} 20)$. A menor diferença de cor foi registrada nas amostras armazenadas à umidade relativa de $60 \%$ (H60) e não registrou-se diferença significativa entre o efeito da umidade relativa de $75 \%$ (H75) e de $93 \%$ (H93).

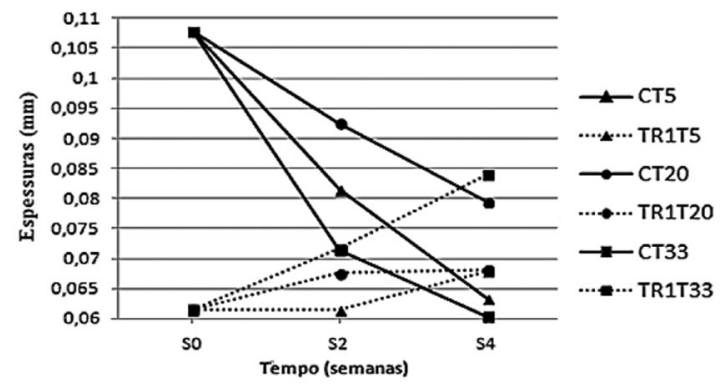

Figura 6. Espessura dos filmes de quitosana armazenados a diferentes umidades: (a) 60\%; (b) 75\%; (c) $93 \%$. C: amostra controle, TR1: mistura dos óleos essenciais de tomilho e alecrim proporção 1:1 em relação à quitosana, S: semanas de armazenamento, T: temperaturas de armazenamento. 


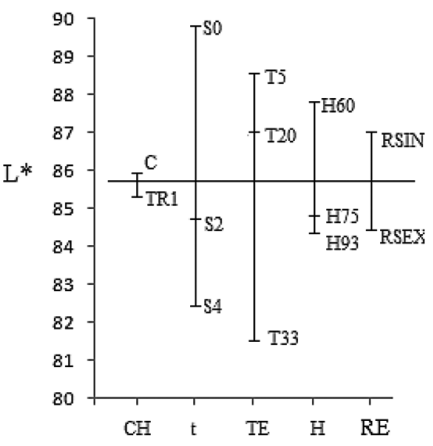

(a)

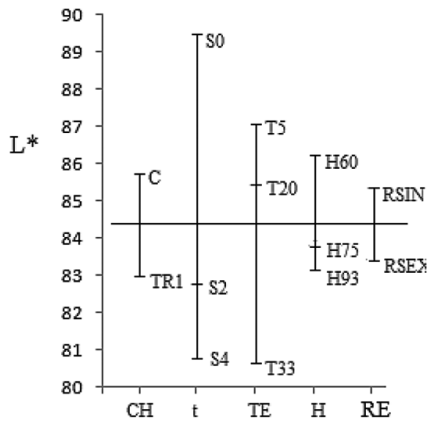

(d)

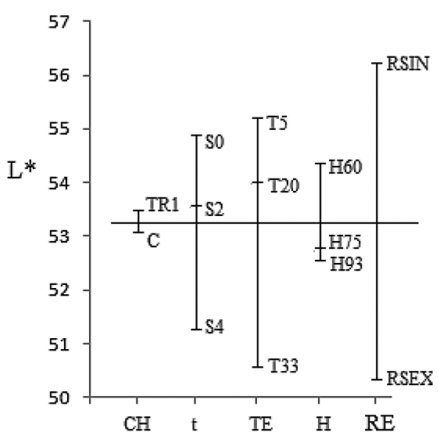

(b)

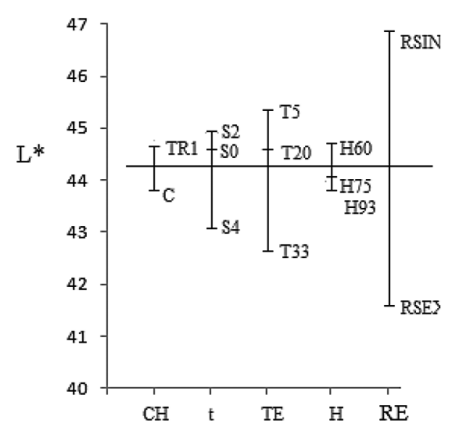

(e)

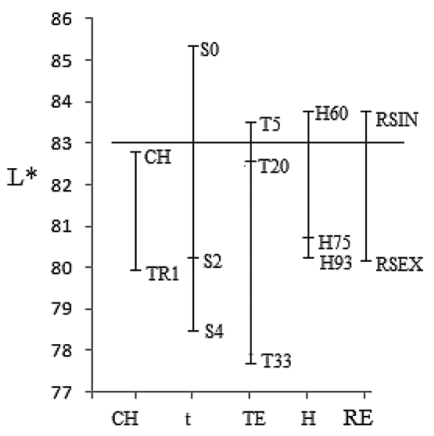

(c)

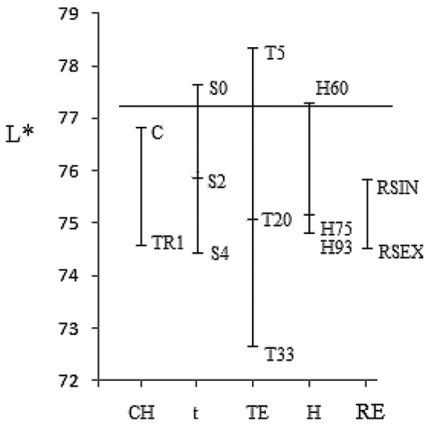

(f)

Figura 7. Efeito da composição dos filmes, do tempo, da temperatura, da umidade e refletância sobre L*: (a) fundo branco; (b) fundo verde; (c) fundo verde maçã; (d) fundo amarelo; (e) fundo vermelho; (f) fundo rosa. L*: luminosidade, C: amostra controle, TR1: mistura dos óleos essenciais de tomilho e alecrim proporção 1:1 em relação à quitosana, S: semanas de armazenamento, T: temperaturas de armazenamento, H: umidade de armazenamento, RSIN: refletância especular incluída, RSEX: refletância especular excluída.

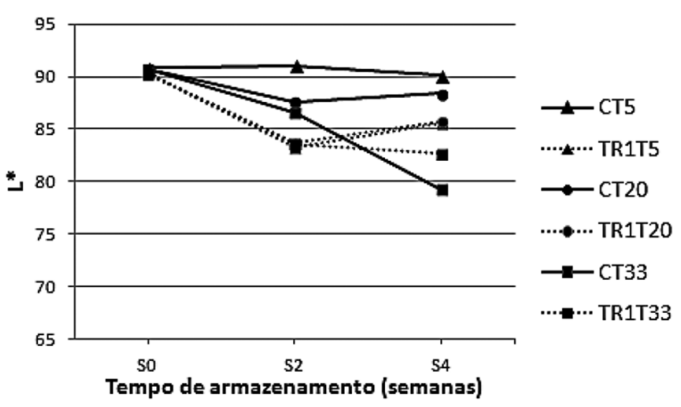

(a)

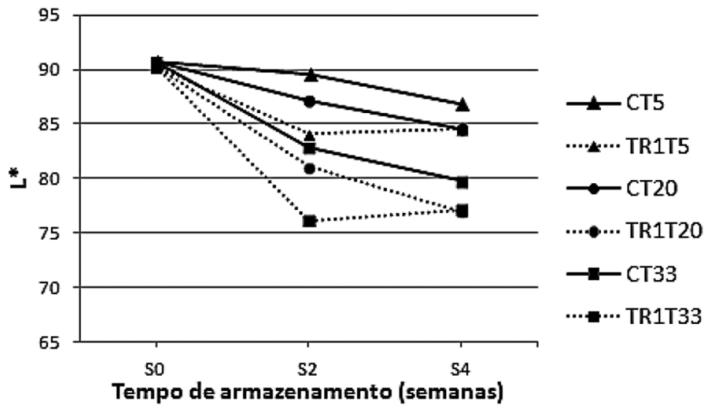

(b)

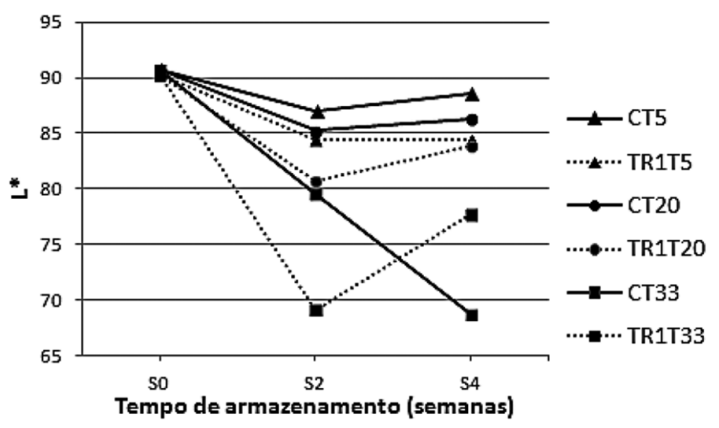

(c)

Figura 8. $L *$ dos filmes de quitosana armazenados a diferentes umidades: (a) $60 \%$; (b) $75 \%$; (c) $93 \%$. L*: luminosidade medida por RSIN no fundo amarelo, C: amostra controle, TR1: mistura dos óleos essenciais de tomilho e alecrim proporção 1:1 em relação à quitosana, $\mathrm{S}$ : semanas de armazenamento, T: temperaturas de armazenamentos. 


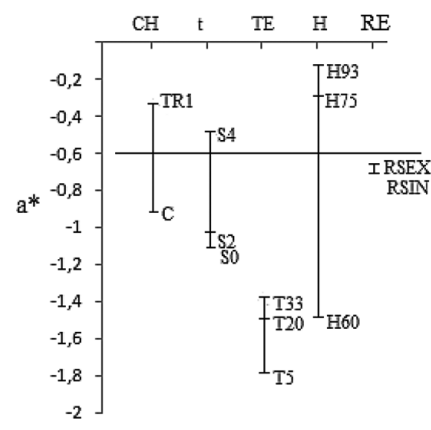

(a)

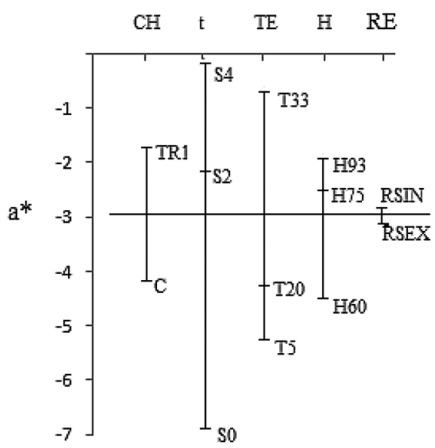

(d)

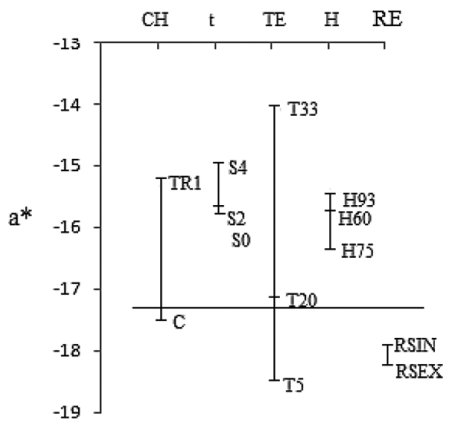

(b)

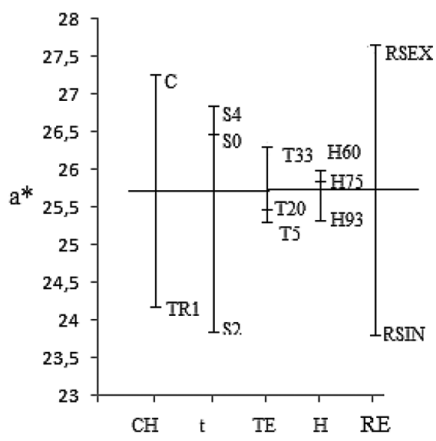

(e)

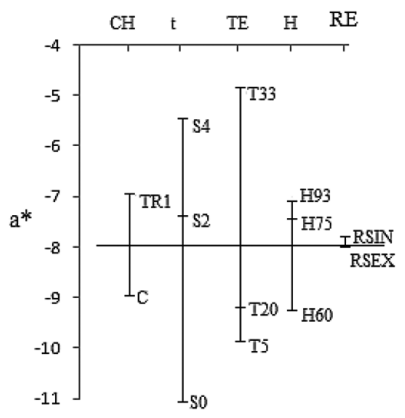

(c)

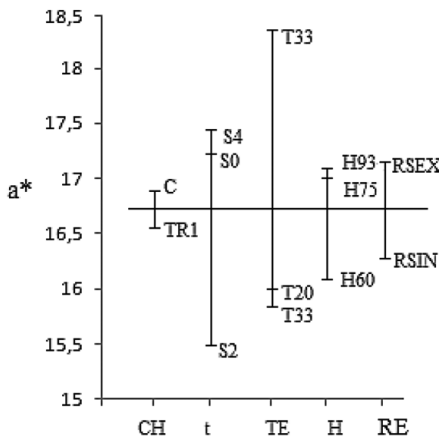

(f)

Figura 9. Efeito da composição dos filmes $(\mathrm{CH})$, do tempo (t), da temperatura (TE), da umidade $(\mathrm{H})$ e refletância (RE) sobre a*: (a) fundo branco; (b) fundo verde; (c) fundo verde maçã; (d) fundo amarelo; (e) fundo vermelho; (f) fundo rosa. a*: intensidade de vermelho e verde, C: amostra controle, TR1: mistura dos óleos essenciais de tomilho e alecrim proporção 1:1 em relação à quitosana, $\mathrm{S}$ : semana de armazenamento, T: temperatura de armazenamento, H: umidade de armazenamento, RSIN: refletância especular incluída, RSEX: refletância especular excluída.

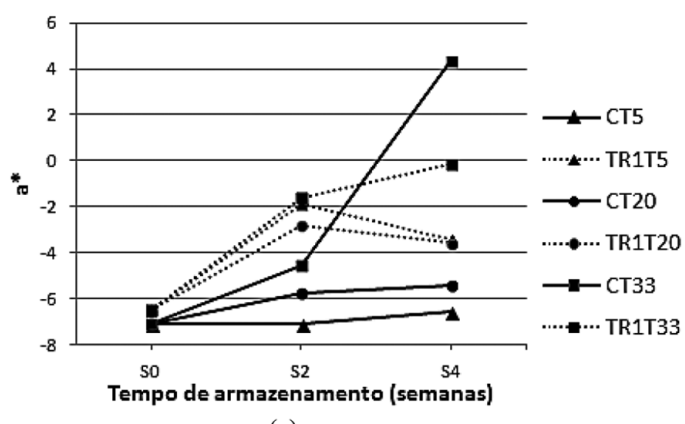

(a)

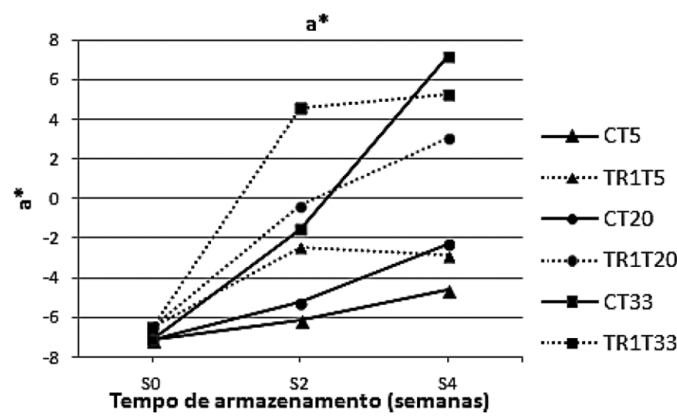

(b)

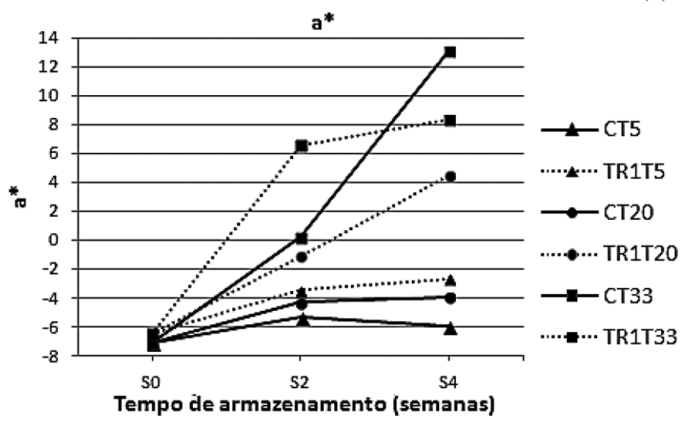

(c)

Figura 10. a* dos filmes de quitosana armazenados a diferentes umidades: (a) 60\%; (b) $75 \%$; (c) $93 \%$. a*: intensidade de vermelho e verde medida por RSIN no fundo amarelo. C: amostra controle, TR1: mistura dos óleos essenciais de tomilho e alecrim proporção 1:1 em relação à quitosana, $\mathrm{S}$ : semanas de armazenamento, T: temperaturas de armazenamento. 


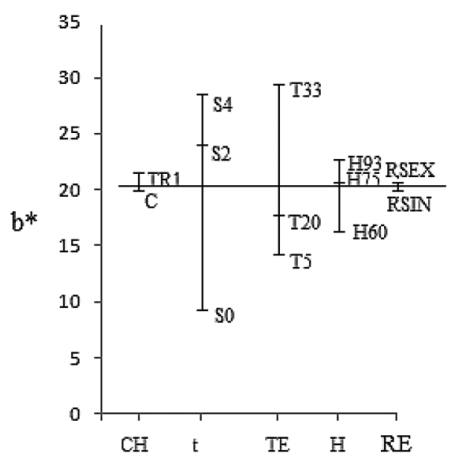

(a)

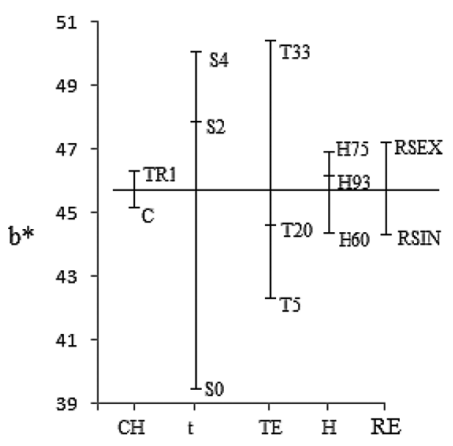

(d)

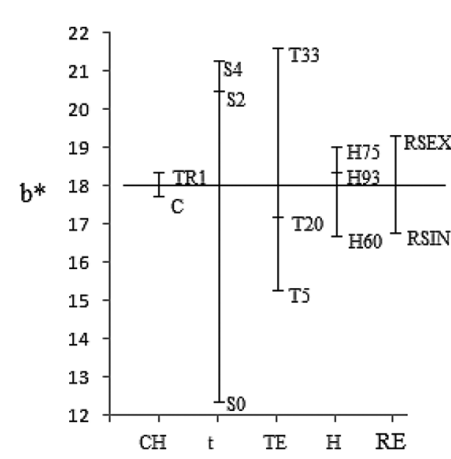

(b)

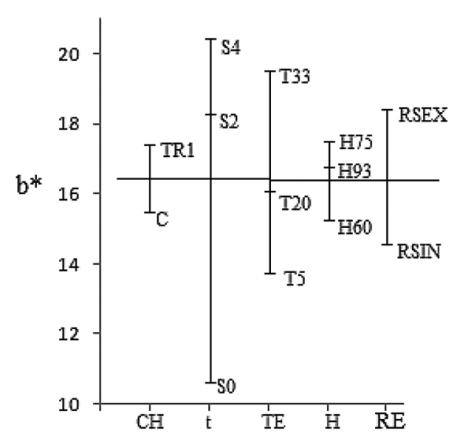

(e)

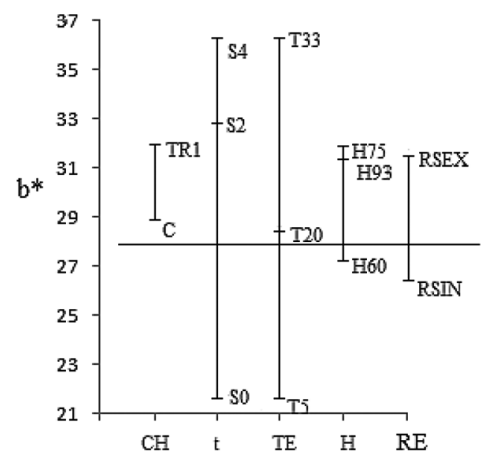

(c)

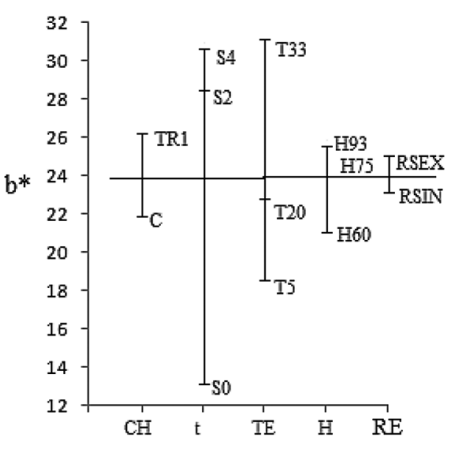

(f)

Figura 11. Efeito da composição dos filmes $(\mathrm{CH})$, do tempo (t), da temperatura (TE), da umidade (H) e refletância (RE) sobre $b^{*}$ : (a) fundo branco; (b) fundo verde; (c) fundo verde maçã; (d) fundo amarelo; (e) fundo vermelho; (f) fundo rosa. b*: intensidade de amarelo a azul, C: amostra controle, TR1: mistura dos óleos essenciais de tomilho e alecrim proporção 1:1 em relação à quitosana, S: semana de armazenamento, T: temperatura de armazenamento, H: umidade de armazenamento, RSIN: refletância especular incluída, RSEX: refletância especular excluída.

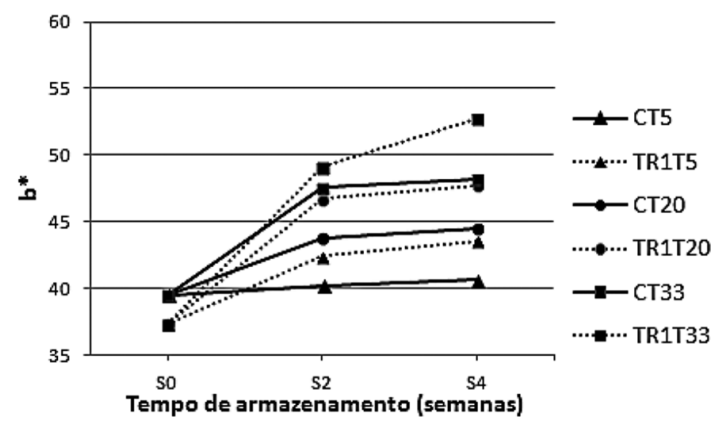

(a)

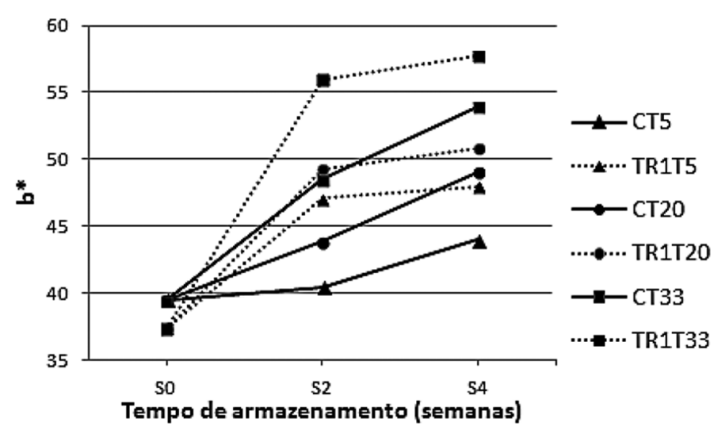

(b)

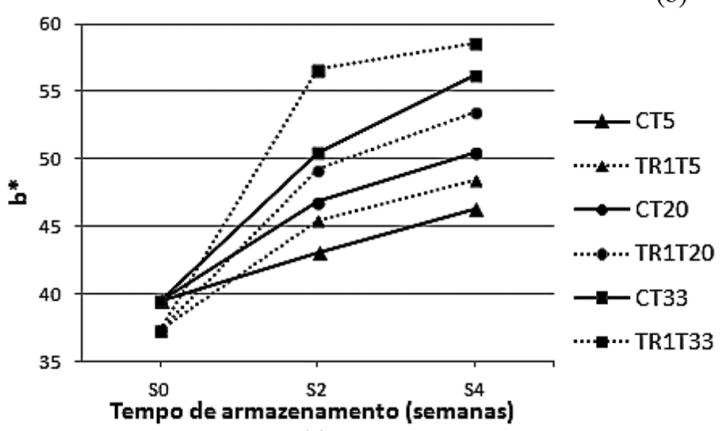

(c)

Figura 12. $b^{*}$ dos filmes de quitosana armazenados a diferentes umidades: (a) $60 \%$; (b) $75 \%$; (c) $93 \%$. b*: intensidade de amarelo a azul medida por RSIN no fundo amarelo, C: amostra controle, TR1: mistura dos óleos essenciais de tomilho e alecrim proporção 1:1 em relação à quitosana, $\mathrm{S}$ : semanas de armazenamento, T: temperaturas de armazenamento. 


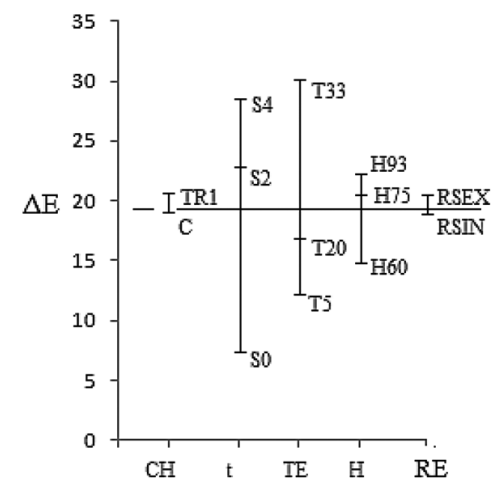

(a)

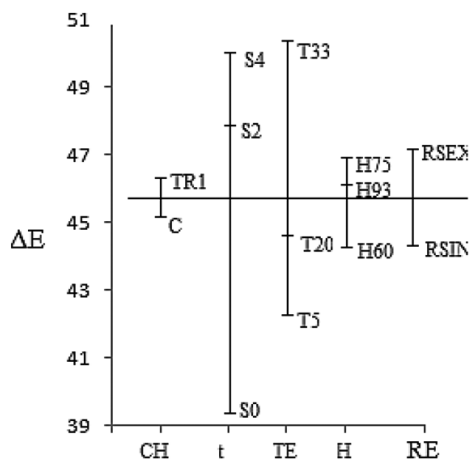

(d)

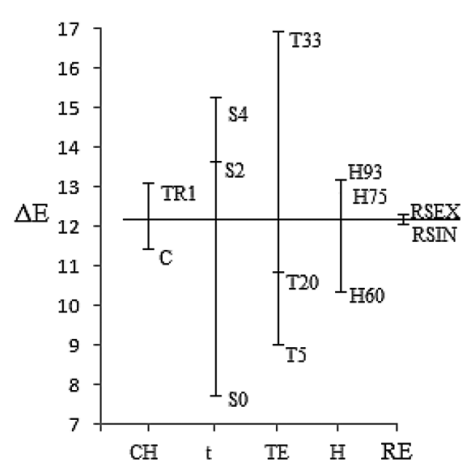

(b)

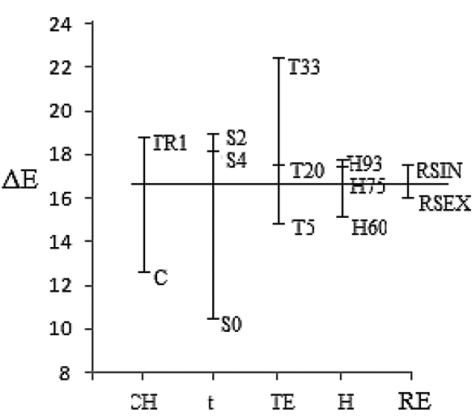

(e)

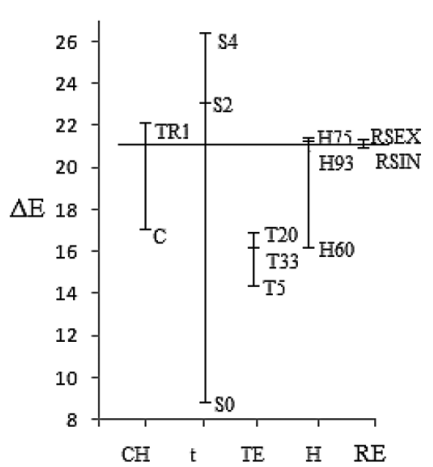

(c)

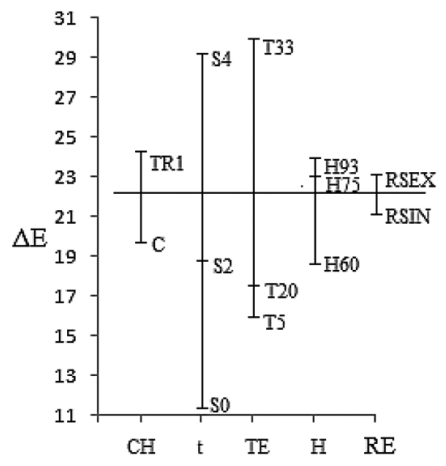

(f)

Figura 13. Efeito da composição dos filmes $(\mathrm{CH})$, do tempo (t), da temperatura (TE), da umidade $(\mathrm{H})$ e refletância (RE) sobre $\Delta \mathrm{E}$ : (a) fundo branco; (b) fundo verde; (c) fundo verde maçã; (d) fundo amarelo; (e) fundo vermelho; (f) fundo rosa. $\Delta \mathrm{E}$ : diferença de cor, C: amostra controle, TR1: mistura dos óleos essenciais de tomilho e alecrim proporção 1:1 em relação à quitosana, S: semana de armazenamento, T: temperatura de armazenamento, H: umidade de armazenamento, RSIN: refletância especular incluída, RSEX: refletância especular excluída.

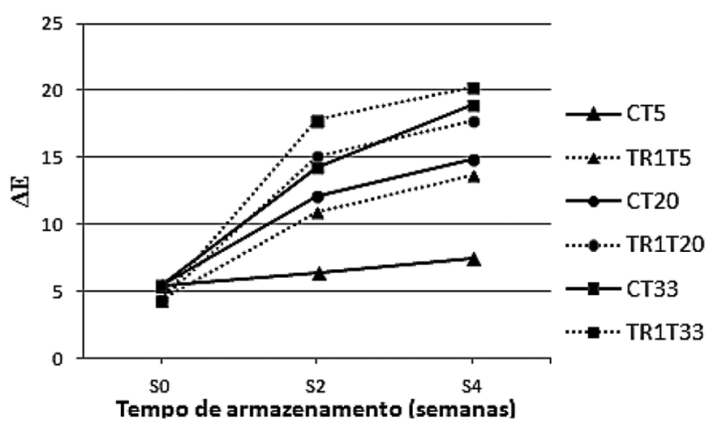

(a)

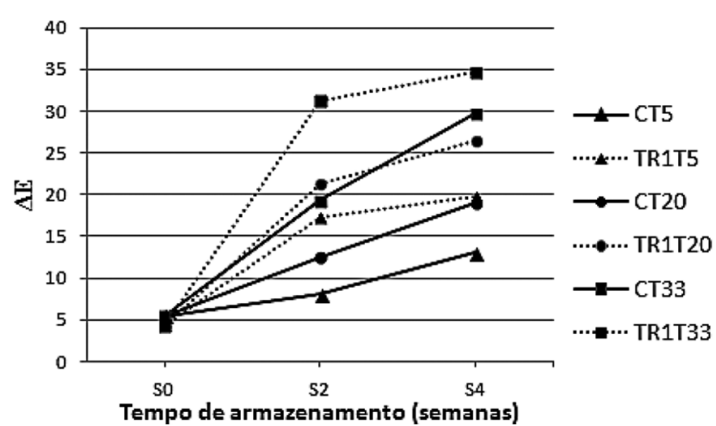

(b)

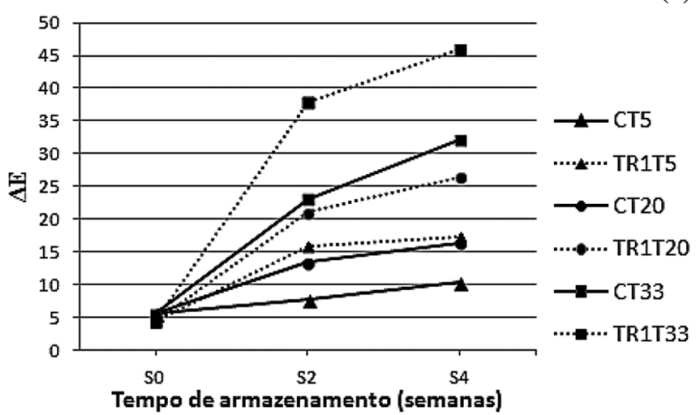

(c)

Figura 14. $\Delta \mathrm{E}$ dos filmes de quitosana armazenados a diferentes umidades: (a) $60 \%$; (b) $75 \%$; (c) $93 \%$. $\Delta \mathrm{E}$ : diferença de cor, $\mathrm{C}$ : amostra controle, TR1: mistura dos óleos essenciais de tomilho e alecrim proporção 1:1 em relação à quitosana, S: semanas de armazenamento, $\mathrm{T}$ : temperaturas de armazenamento. 
No padrão amarelo, o parâmetro b* registrou diferenças significativas entre a composição dos filmes, as temperaturas $5^{\circ}, 20^{\circ} \mathrm{C}$ e $33^{\circ} \mathrm{C}$, as umidades de $60 \%$ e $75 \%$, e entre $75 \%$ e $93 \%$ na temperatura de $33^{\circ} \mathrm{C}$, além de registrar diferenças significativas entre as amostras armazenadas da Semana 0,2 e 4 ( $\mathrm{S} 0, \mathrm{~S} 2$ e S4, respectivamente), sob umidade de armazenamento de $93 \%$ (Figura 14). A diminuição do parâmetro $L^{*}$ e o incremento do parâmetro $b^{*}$ foram os fatores que afetaram o cálculo e o a resposta dessa propriedade ${ }^{[45]}$.

\section{Conclusões}

Os resultados desta pesquisa demonstraram que os parâmetros da cor mudaram com a inclusão de óleos essenciais de tomilho e alecrim e as suas combinações, assim como com o armazenamento. Quando os óleos essenciais são incluídos nos filmes, aumenta a intensidade amarela $\left(b^{*}\right)$ e diminui-se a luminosidade $\left(L^{*}\right)$. Igualmente, o armazenamento diminuíram os valores de $\mathrm{L}^{*}$, mas aumentariam os valores de $\mathrm{a}^{*} \mathrm{e} \mathrm{b}^{*}$ na maioria dos casos, o qual ocasiona uma diminuição do brilho superficial e um aumento dos matizes amarelo e vermelho. Além disso, a inclusão e o aumento da concentração de óleos essenciais incrementam a diferença de cor $(\Delta \mathrm{E})$ pela leve diminuição do parâmetro $\mathrm{L}^{*} \mathrm{e}$ ao leve incremento do parâmetro $\mathrm{b}^{*}$.

Esses resultados sugerem que os filmes não conservam as propriedades da cor estável nem com a modificação da sua composição nem com o armazenamento. Esses comportamentos limitam as possíveis aplicações de quitosana como filme ou recobrimento para a indústria de embalagens de alimentos.

\section{Agradecimentos}

Os autores agradecem ao Departamento Administrativo de Ciencia, Tecnología e Innovación (Colciencias) e à Dirección de Investigación da Universidad Nacional de Colombia Sede Bogotá pelo o suporte econômico.

\section{Referências}

1. Dutta, J., Tripathi, S., \& Dutta, P. K. (2012). Progress in antimicrobial activities of chitin, chitosan and its oligosaccharides: a systematic study needs for food applications. Food Science \& Technology International, 18(1), 3-34. http://dx.doi. org/10.1177/1082013211399195. PMid:21954316.

2. Kenawy, R., Worley, S. D., \& Broughton, R. (2007). The chemistry and applications of antimicrobial polymers: a stateof-the-art review. Biomacromolecules, 8(5), 1359-1384. http:// dx.doi.org/10.1021/bm061150q. PMid:17425365.

3. Kong, M., Chen, X. G., Xing, K., \& Park, H. J. (2010). Antimicrobial properties of chitosan and mode of action: a state of the art review. International Journal of Food Microbiology, 144(1), 51-63. http://dx.doi.org/10.1016/j. ijfoodmicro.2010.09.012. PMid:20951455

4. Rabea, E. I., Badawy, M. E. T., Stevens, C. V., Smagghe, G., \& Steurbaut, W. (2003). Chitosan as antimicrobial agent: applications and mode of action. Biomacromolecules, 4(6), 1457-1465. http://dx.doi.org/10.1021/bm034130m. PMid:14606868.

5. Cunha, A. G., \& Gandini, A. (2010). Turning polysaccharides into hydrophobic materials: a critical review. Part 2. Hemicelluloses, chitin/chitosan, starch, pectin and alginates. Cellulose, 17(6), 1045-1065. http://dx.doi.org/10.1007/s10570-010-9435-5.
6. Moradi, M., Tajik, H., Rohani, S. M. R., Oromiehie, A. R., Malekinejad, H., Aliakbarlu, J., \& Hadian, M. (2012). Characterization of antioxidant chitosan film incorporated with Zataria multiflora Boiss essential oil and grape seed extract. LWT - Food Science and Technology, 46(2), 477-484. http:// dx.doi.org/10.1016/j.1wt.2011.11.020.

7. Altiok, D., Altiok, E., \& Tihminlioglu, F. (2010). Physical, antibacterial and antioxidant properties of chitosan films incorporated with thyme oil for potential wound healing applications. Journal of Materials Science: Materials in Medicine, 21(7), 2227-2236. http://dx.doi.org/10.1007/s10856010-4065-x. PMid:20372985.

8. Du, W. X., Olsen, C. W., Avena-Bustillos, R. J., Friedman, M., \& McHugh, T. H. (2011). Physical and antibacterial properties of edible films formulated with apple skin polyphenols. Journal of Food Science, 76(2), M149-M155. http://dx.doi. org/10.1111/j.1750-3841.2010.02012.x. PMid:21535779.

9. Sanchez-Gonzalez, L., Chiralt, A., Gonzalez-Martinez, C., \& Chafer, M. (2011). Effect of essential oils on properties of film forming emulsions and films based on hydroxypropylmethylcellulose and chitosan. Journal of Food Engineering, 105(2), 246-253. http://dx.doi.org/10.1016/j.jfoodeng.2011.02.028.

10. Zhong, Y., \& Li, Y. F. (2011). Effects of storage conditions and acid solvent types on structural, mechanical and physical properties of kudzu starch (Pueraria lobata)-chitosan composite films. Starch, 63(9), 579-586. http://dx.doi.org/10.1002/ star.201100019.

11. Caner, C., Vergano, P. J., \& Wiles, J. L. (1998). Chitosan film mechanical and permeation properties as affected by acid, plasticizer, and storage. Journal of Food Science, 63(6), 10491053. http://dx.doi.org/10.1111/j.1365-2621.1998.tb15852.x.

12. Kerch, G., \& Korkhov, V. (2011). Effect of storage time and temperature on structure, mechanical and barrier properties of chitosan-based films. European Food Research and Technology, 232(1), 17-22. http://dx.doi.org/10.1007/s00217-010-1356-x.

13. Suyatma, N. E., Tighzert, L., Copinet, A., \& Coma, V. (2005). Effects of hydrophilic plasticizers on mechanical, thermal, and surface properties of chitosan films. Journal of Agricultural and Food Chemistry, 53(10), 3950-3957. http://dx.doi.org/10.1021/ jf048790+. PMid:15884822.

14. Nud'ga, L., Petrova, V., Gofman, I., Abalov, I., Volchek, B., Vlasova, E., \& Baklagina, Y. (2008). Chemical and structural transformations in chitosan films in the course of storage. Russian Journal of Applied Chemistry, 81(11), 1992-1996. http://dx.doi.org/10.1134/S1070427208110244.

15. Artharn, A., Prodpran, T., \& Benjakul, S. (2009). Round scad protein-based film: Storage stability and its effectiveness for shelf-life extension of dried fish powder. Lwt-. Journal of Food Science and Technology, 42(7), 1238-1244. http://dx.doi. org/10.1016/j.1wt.2008.08.009.

16. Vasilatos, G. C., \& Savvaidis, I. N. (2013). Chitosan or rosemary oil treatments, singly or combined to increase turkey meat shelf-life. International Journal of Food Microbiology, 166(1), 54-58. http://dx.doi.org/10.1016/j.ijfoodmicro.2013.06.018. PMid:23827808.

17. Giatrakou, V., Ntzimani, A., \& Savvaidis, E. N. (2010). Combined chitosan-thyme treatments with modified atmosphere packaging on a ready-to-cook poultry product. Journal of Food Protection, 73(4), 663-669. PMid:20377954.

18. Caner, C. (2005). The effect of edible eggshell coatings on egg quality and consumer perception. Journal of the Science of Food and Agriculture, 85(11), 1897-1902. http://dx.doi. org/10.1002/jsfa.2185.

19. Sathivel, S. (2005). Chitosan and protein coatings affect yield, moisture loss, and lipid oxidation of pink salmon (Oncorhynchus gorbuscha) fillets during frozen storage. 
Journal of Food Science, 70(8), E455-E459. http://dx.doi. org/10.1111/j.1365-2621.2005.tb11514.x.

20. Ansorena, M. R., Marcovich, N. E., \& Roura, S. I. (2011). Impact of edible coatings and mild heat shocks on quality of minimally processed broccoli (Brassica oleracea L.) during refrigerated storage. Postharvest Biology and Technology, 59(1), 53-63. http://dx.doi.org/10.1016/j.postharvbio.2010.08.011.

21. Sangsuwan, J., Rattanapanone, N., \& Rachtanapun, P. (2008). Effect of chitosan/methyl cellulose films on microbial and quality characteristics of fresh-cut cantaloupe and pineapple. Postharvest Biology and Technology, 49(3), 403-410. http:// dx.doi.org/10.1016/j.postharvbio.2008.02.014.

22. Hojo, E. T. D., Durigan, J. F., \& Hojo, R. H. (2011). Use of plastic packaging and coverage of chitosan in the postharvest conservation of litchi. Revista Brasileira de Fruticultura, 33, 377-383. http://dx.doi.org/10.1590/S0100-29452011000500048.

23. Salvador-Figueroa, M., Aragon-Gomez, W. I., Hernandez-Ortiz, E., Vazquez-Ovando, J. A., \& Adriano-Anaya, M. D. (2011). Effect of chitosan coating on some characteristics of mango (Mangifera indica L.) "Ataulfo" subjected to hydrothermal process. African Journal of Agricultural Research, 6(27), 5800-5807.

24. Chien, P. J., Sheu, F., \& Yang, F. H. (2007). Effects of edible chitosan coating on quality and shelf life of sliced mango fruit. Journal of Food Engineering, 78(1), 225-229. http://dx.doi. org/10.1016/j.jfoodeng.2005.09.022.

25. Ali, A., Muhammad, M. T. M., Sijam, K., \& Siddiqui, Y. (2011). Effect of chitosan coatings on the physicochemical characteristics of Eksotika II papaya (Carica papaya L.) fruit during cold storage. Food Chemistry, 124(2), 620-626. http:// dx.doi.org/10.1016/j.foodchem.2010.06.085.

26. Wardy, W., Pujols Martínez, K. D., Xu, Z., No, H. K., \& Prinyawiwatkul, W. (2014). Viscosity changes of chitosan solution affect physico-functional properties and consumer perception of coated eggs during storage. LWT-Food Science and Technology, 55(1), 67-73. http://dx.doi.org/10.1016/j. lwt.2013.07.013.

27. Hernández-Muñoz, P., Almenar, E., Valle, V. D., Velez, D., \& Gavara, R. (2003). Effect of chitosan coating combined with postharvest calcium treatment on strawberry (Fragaria ananassa) quality during refrigerated storage. Journal of Food Chemestry, 110(2), 428-435. http://dx.doi.org/10.1016/j. foodchem.2008.02.020.

28. Kim, K. W., Min, B. J., Kim, Y.-T., Kimmel, R. M., Cooksey, K., $\&$ Park, S. I. (2011). Antimicrobial activity against foodborne pathogens of chitosan biopolymer films of different molecular weights. LWT - Food Science and Technology, 44(2), 565-569. http://dx.doi.org/10.1016/j.lwt.2010.08.001.

29. Hernandez-Ochoa, L., Gonzales-Gonzales, A., GutiérrezMendez, N., Muñoz-Castellanos, L. N., \& Quintero-Ramos, A. (2011). Study of the antibacterial activity of chitosan-based films prepared with different molecular weights including spices essential oils and functional extracts as antimicrobial agents. Revista Mexicana de Ingeniería Quimica, 10(3), 455-463.

30. Oms-Oliu, G., Soliva-Fortuny, R., \& Martín-Belloso, O. (2008). Using polysaccharide-based edible coatings to enhance quality and antioxidant properties of fresh-cut melon. LWT - Food Science and Technology, 4l(10), 1862-1870. http://dx.doi. org/10.1016/j.1wt.2008.01.007.

31. Perez-Gago, M. B., Serra, M., \& Río, M. A. (2006). Color change of fresh-cut apples coated with whey protein concentrate-based edible coatings. Postharvest Biology and Technology, 39(1), 84-92. http://dx.doi.org/10.1016/j.postharvbio.2005.08.002.

32. Tzoumaki, M. V., Biliaderis, C. G., \& Vasilakakis, M. (2007). Impact of edible coatings and packaging on quality of white asparagus (Asparagus officinalis, L.) during cold storage.
Food Chemistry, 117(1), 55-63. http://dx.doi.org/10.1016/j. foodchem.2009.03.076.

33. Lee, Y. K., \& Powers, M. V. (2007). Color changes of resin composites in the reflectance and transmittance modes. Dental Materials, 23(3), 259-264. http://dx.doi.org/10.1016/j. dental.2006.01.019. PMid:16519927.

34. Nakamura, T., Saito, O., Mizuno, M., Kinuta, S., \& Ishigaki, S. (2003). Influence of abutment substrates on the colour of metal free polymer crowns. Journal of Oral Rehabilitation, 30(2), 184-188. http://dx.doi.org/10.1046/j.1365-2842.2003.01019.x. PMid:12535146.

35. Sánchez-Zapata, E., Fuentes-Zaragoza, E., Navarro-Rodríguez de Vera, C., Sayas, E., Sendra, E., Fernández-López, J., \& Pérez-Alvarez, J. A. (2011). Effects of tuna pâté thickness and background on CIELa* ${ }^{*}$ color parameters and reflectance spectra. Food Control, 22(8), 1226-1232. http://dx.doi. org/10.1016/j.foodcont.2011.01.022.

36. Lee, Y. K., Lim, B. S., \& Kim, C. W. (2005). Difference in the colour and colour change of dental resin composites by the background. Journal of Oral Rehabilitation, 32(3), 227233. http://dx.doi.org/10.1111/j.1365-2842.2004.01402.x. PMid:15707434.

37. Srinivasa, P. C., Ramesh, M. N., Kumar, K. R., \& Tharanathan, R. N. (2003). Properties and sorption studies of chitosanpolyvinyl alcohol blend films. Carbohydrate Polymers, 53(4), 431-438. http://dx.doi.org/10.1016/S0144-8617(03)00105-X.

38. Deng, Y., Zhu, L. W., Luo, W., Xiao, C. L., Song, X. Y., \& Chen, J. S. (2009). Changes in physical properties of chitosan films at subzero temperatures. Italian Journal of Food Science, 21(4), 487-497.

39. Abugoch, L., Tapia, C., Villaman, M. C., Yazdani-Pedram, M., \& Diaz-Dosque, M. (2011). Characterization of quinoa protein-chitosan blend edible films. Food Hydrocolloids, 25(5), 879-886. http://dx.doi.org/10.1016/j.foodhyd.2010.08.008.

40. Sánchez-González, L., Cháfer, M., Chiralt, A., \& GonzalezMartinez, C. (2009). Physical properties of edible chitosan films containing bergamot essential oil and their inhibitory action on Penicillium italicum. Carbohydrate Polymers, 82(2), 277-283. http://dx.doi.org/10.1016/j.carbpol.2010.04.047.

41. Hosseini, M. H., Razavi, S. H., \& Mousavi, M. A. (2009). Antimicrobial, physical and mechanical properties of chitosanbased films incorporated with thyme, clove and cinnamon essential oils. Journal of Food Processing and Preservation, 33(6), 727-743. http://dx.doi.org/10.1111/j.1745-4549.2008.00307.x.

42. Du, W. X., Olsen, C. W., Avena-Bustillos, R. J., McHugh, T. H., Levin, C. E., \& Friedman, M. (2009). Effects of allspice, cinnamon, and clove bud essential oils in edible apple films on physical properties and antimicrobial activities. Journal of Food Science, 74(7), M372-M378. http://dx.doi.org/10.1111/j.17503841.2009.01282.x. PMid:19895483.

43. Moradi, M., Tajik, H., Rohani, S. M. R., \& Oromiehie, A. R. (2011). Effectiveness of Zataria multiflora Boiss essential oil and grape seed extract impregnated chitosan film on ready-to-eat mortadella-type sausages during refrigerated storage. Journal of the Science of Food and Agriculture, 91(15), 2850-2857. http://dx.doi.org/10.1002/jsfa.4531. PMid:21796636.

44. Sánchez-González, L., Vargas, M., González-Martínez, C., Chiralt, A., \& Cháfer, M. (2009). Characterization of edible films based on hydroxypropylmethylcellulose and tea tree essential oil. Food Hydrocolloids, 23(8), 2102-2109. http:// dx.doi.org/10.1016/j.foodhyd.2009.05.006.

45. Moreno-Osorio, L., Garcia, M., \& Villalobos-Carvajal, R. (2010). Effect of polygodial on mechanical, optical and barrier properties of chitosan films. Journal of Food Processing and Preservation, 34(2), 219-234. http://dx.doi.org/10.1111/j.17454549.2009.00373.x. 
46. Fernandez-Saiz, P., Lagaron, J. M., \& Ocio, M. J. (2009). Optimization of the film-forming and storage conditions of chitosan as an antimicrobial agent. Journal of Agricultural and Food Chemistry, 57(8), 3298-3307. http://dx.doi.org/10.1021/ jf8037709. PMid:19281273.

47. Duan, J., Kim, K., Daeschel, M. A., \& Zhao, Y. (2008). Storability of antimicrobial chitosan-lysozyme composite coating and film-forming solutions. Journal of Food Science, 73(6), M321-M329. http://dx.doi.org/10.1111/j.17503841.2008.00849.x. PMid:19241565.

48. Cuq, B., Gontard, N., Cuq, J.-L., \& Guilbert, S. (1996). Stability of myofibrillar protein-based biopackagings during storage.
LWT - Food Science and Technology, 29(4), 344-348. http:// dx.doi.org/10.1006/fstl.1996.0052.

49. Hernández-Muñoz, P., López-Rubio, A., del-Valle, V., Almenar, E., \& Gavara, R. (2003). Mechanical and water barrier properties of glutenin films influenced by storage time. Journal of Agricultural and Food Chemesty, 52(1), 79-83. http://dx.doi. org/10.1021/jf034763s.

Enviado: Dez. 09, 2014

Revisado: Mar. 17, 2015 Aceito: Abr. 29, 2015 